\title{
Patterns and determinants of compliance with inhaled steroids in adults with asthma
}

\author{
Yves Lacasse MD MSc ${ }^{1}$, Hélène Archibald MD², Pierre Ernst MD MSc ${ }^{3}$, Louis-Philippe Boulet MD ${ }^{1}$
}

Y Lacasse, H Archibald, P Ernst, L-P Boulet. Patterns and determinants of compliance with inhaled steroids in adults with asthma. Can Respir J 2005;12(4):211-217.

BACKGROUND: Patient compliance with inhaled corticosteroids (ICS) in asthma is considered to be suboptimal.

OBJECTIVES: To describe the patterns of compliance with ICS and identify factors determining the compliance to ICS in adults with asthma.

METHODS: Based on a review of the literature and interviews with asthmatic patients who require the regular use of ICS, potential determinants of compliance to ICS were identified. Questionnaires related to these determinants were then administered to a cohort of patients from three subspecialty clinics, including two from universityaffiliated centres. Patients with mild-to-moderate asthma who were 15 years of age and older and required (from the physician's point of view) ICS as maintenance medication because of persistent asthma were included in the study. Patients were followed for a period of 12 weeks. Compliance was measured using electronic devices.

RESULTS: Data from 124 patients ( 51 men; mean age $47 \pm 15$ years; mean prescribed daily dose of ICS [fluticasone propionate] $643 \pm 385 \mu \mathrm{g}$ ) were analyzed. On average, the patients took $72 \pm 24 \%$ of their prescription. Four patterns of compliance were observed and are described: $1 \mathrm{~A}-$ regular compliance $(n=29) ; 1 B$ - irregular compliance $(n=37) ; 2 A-$ regular noncompliance $(\mathrm{n}=24)$; and $2 \mathrm{~B}$ - irregular noncompliance $(n=34)$. Among the potential predictors of noncompliance, age was the only significant predictor (compliance increased with increasing age). There was no difference in asthma control between compliant and noncompliant patients.

CONCLUSION: Compliance to ICS in patients with asthma is often suboptimal and difficult to predict. The observations suggest that some asthmatics may be overtreated with ICS.

Key Words: Asthma; Compliance; Inhaled corticosteroids

Compliance is usually defined as the extent to which a perUn's behaviour (in terms of taking medication, following diets or executing lifestyle changes) coincides with medical or health recommendations (1). In studying compliance, clinicians and researchers must assume that the diagnosis is correct and the recommendations are appropriate, effective and manageable by the patient (2). The most recent guidelines (3) regarding the management of asthma emphasized the avoidance of triggering environmental agents and the use of antiinflammatory medication in patients with persistent symptoms. Inhaled corticosteroids (ICS) represent the mainstay

\section{Habitudes et facteurs déterminants dans la fidélité des adultes asthmatiques à leur corticothérapie par inhalation}

HISTORIQUE : Dans l'asthme, la fidélité des patients à leur corticothérapie par inhalation (CTI) est généralement jugée insatisfaisante. OBJECTIFS : Décrire les habitudes des patients quant à la fidélité à leur CTI et identifier les facteurs de l'observance thérapeutique chez les adultes asthmatiques.

MÉTHODES : Sur la base d'une revue de littérature et d'entrevues réalisées auprès de patients asthmatiques qui ont régulièrement recours à la CTI, certains facteurs potentiels de l'observance thérapeutique vis-à-vis de la CTI ont été identifiés. Des questionnaires portant sur ces facteurs ont ensuite été administrés à une cohorte de patients provenant de trois cliniques spécialisées, y compris deux centres universitaires. Les patients atteints d'un asthme de léger à modéré âgés de 15 ans et plus qui nécessitaient (du point de vue du médecin) une CTI en traitement d'entretien à cause d'un asthme persistant ont été inclus dans l'étude. Les patients ont été suivis pendant une période de 12 semaines. L'observance thérapeutique a été mesurée au moyen d'instruments électroniques.

RÉSULTATS : Les données provenant de 124 patients ( 51 hommes; âge moyen $47 \pm 15$ ans; devant prendre en moyenne $643 \pm 385 \mu$ de CTI par jour (propionate de fluticasone) ont été analysées. En moyenne, les patients prenaient $72 \pm 24 \%$ de la dose prescrite. On a observé et décrit quatre types d'observance thérapeutique : $1 \mathrm{~A}$ - observance régulière $(\mathrm{n}=29)$; $1 \mathrm{~B}$ - observance irrégulière $(\mathrm{n}=37) ; 2 \mathrm{~A}$ - non-observance régulière $(\mathrm{n}=24)$ et $2 \mathrm{~B}$ - non-observance irrégulière $(\mathrm{n}=34)$. Parmi les facteurs potentiels de non-observance thérapeutique, l'âge a été le seul facteur de prévisibilité significatif (l'observance augmentait avec l'âge). On n'a noté aucune différence quant au contrôle de l'asthme entre les patients fidèles à leur traitement et ceux qui ne l'étaient pas.

CONCLUSION : L'observance thérapeutique à l'endroit de la CTI chez les patients asthmatiques est souvent suboptimale et difficile à prédire. Selon les observations, certains asthmatiques recevraient trop de CTI.

of anti-inflammatory therapy for asthma. Evidence of the effectiveness of ICS in reducing bronchial hyperresponsiveness and in improving asthma-related symptoms, control of the disease and quality of life has accumulated (4-7). Most trials include highly selected patients within the framework of study protocols; however, daily practice suggests that compliance with ICS is usually suboptimal.

Several factors have been proposed to explain the gap between the treatment prescribed and the actual use of the medication $(2,8)$. These factors include the complexity of the treatment regimen, lack of knowledge regarding the drug indications

${ }^{1}$ Centre de recherche, Centre de Pneumologie, Hôpital Laval, Institut universitaire de cardiologie et de pneumologie de l'Université Laval, Ste-Foy;

${ }^{2}$ Service de pneumologie, Complexe hospitalier de la Sagamie, Saguenay; ${ }^{3}$ Respiratory Division, McGill University Health Centre and Hôpital

Général, Montreal, Quebec

Correspondence: Dr Yves Lacasse, Centre de Pneumologie, Hôpital Laval, 2725 Chemin Ste-Foy, Ste-Foy, Quebec G1V 4 G5.

Telephone 418-656-4747, fax 418-656-4762, e-mail Yves.Lacasse@med.ulaval.ca 


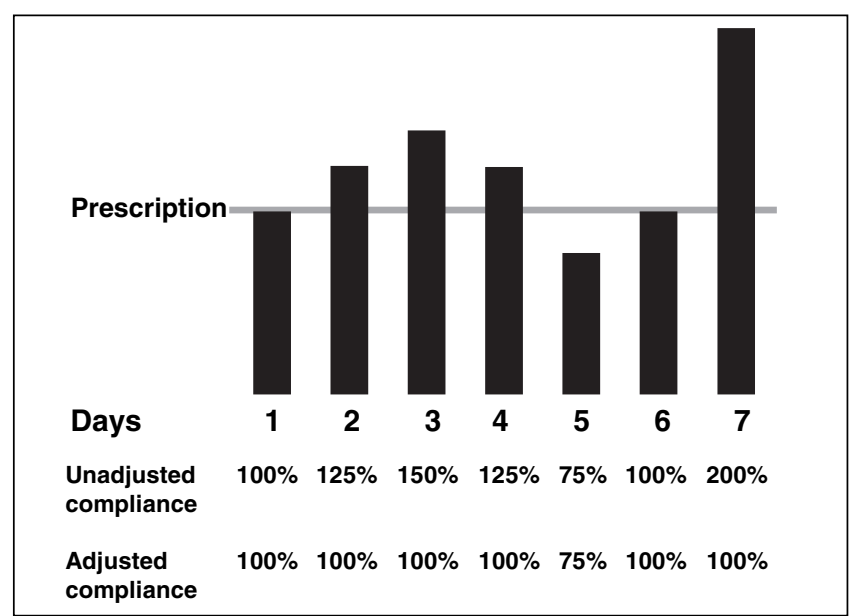

Figure 1) Analysis of compliance. In this example, compliance is examined over a seven-day period. The unadjusted compliance index is the mean of (inhaled/prescribed) $\times 100 \%$ (or $125 \%$, in this example). The daily variation in inhaled corticosteriod use is the SD of the unadjusted compliance index, and is called the regularity index (41\%). To prevent adherence scores from being artificially elevated by including excess usage, the adjusted data consist of no more than the maximum number of puffs prescribed on a given day. The adjusted compliance index is then computed as the mean value for (inhaled/prescribed) $\times 100 \%(96 \%$ in this example)

and mechanisms of action, steroid phobia and other psychological factors that remain ill-defined. However, most studies (2) that have investigated compliance to inhaled medication have been limited because the usual techniques for measuring drugs in biological fluids are only applicable to oral or parenteral drugs. Electronic recording mechanisms have recently been developed to overcome this problem. The objectives of the present study were to describe the patterns of compliance to ICS in adults with asthma using objective measures of drug compliance and to identify the factors that determined compliance to treatment.

\section{PATIENTS AND METHODS}

\section{Patients}

All subjects included in the study fulfilled the American Thoracic Society diagnostic criteria for asthma (9). Eligible patients were 15 years of age or older with mild-to-moderate asthma requiring (from the physician's point of view) ICS as maintenance medication because of persistent asthma for a period of at least 12 consecutive weeks. The investigators did not interfere in the choice of drug therapy to satisfy the inclusion criteria of the study. The prescription was left to the treating physician in agreement with the patient's preference. Therefore, study patients taking dry powder ICS or an inhaler combining ICS and long-acting beta-agonists, those on oral steroids or dependent on someone else for drug administration were excluded.

\section{Potential predictors of compliance}

In a preliminary phase of the study, a comprehensive list of potential determinants of compliance to ICS was generated. These were drawn from a number of sources: a review of the literature on compliance in asthma; consultations with clinicians with extensive experience in evaluating and treating asthmatic patients; and semistructured interviews with patients with asthma. Individual interviews were conducted until five consecutive patients could not contribute any additional items to the list. Whenever possible, a valid questionnaire available from the literature was selected to match each of the elicited potential predictors. All questionnaires were available both in French and English, either from the literature or, for the French versions, from a translation that followed existing guidelines to preserve equivalence (10). This process involved two translations of the questionnaire from English to French; backtranslation of the questionnaire from French to English; comparison of the source and final versions; and pretesting of the French version of the questionnaire using five patients with asthma.

\section{Follow-up study}

A cohort of consecutive, unselected patients with asthma was enrolled in a 12-week observational study. During the study period, patients were not supplied with ICS; instead, the participants used their own medication. This time period was selected because it exceeded the expected duration of a regular 120-dose canister of ICS, allowing for the determination of whether the patients refilled their prescription during the observation period. At study entry, a set of questionnaires was administered to evaluate each of the potential predictors of compliance to ICS elicited in the preliminary phase of the study. From this point on, the patients were not contacted at all by the study personnel. They were not asked to maintain an asthma diary because this might have modified their usual behaviour. The patients' compliance to ICS was then measured using electronic inhalation devices (MDILog II, Model MDC-512, Medtrac Technologies Inc, USA). These microprocessor devices accept a metered-dose inhaler mouthpiece and canister, and record the date and time of each inhaler actuation. The time measurement has a $4 \mathrm{~min}$ resolution. Up to 1320 actuations can be stored in memory, which exceeded the needs of the present study by far. The data can be downloaded through an external interface onto a personal computer. The patients were only told that the total number of puffs taken over the study period would be recorded. Complete information on the time measurement properties of the device was withheld given the obvious bias introduced by the patient's awareness of medication monitoring (11). The use of the monitoring device fulfilled the suggested criteria of behavioural research (12) and received approval by the ethics committee of the three institutions involved in the study. At the end of the 12-week study period, the Asthma Control Questionnaire (13) and the Self-reported Medication-taking Scale (14) were administered. Finally, the study participants were asked to estimate the proportion of the prescribed doses they had inhaled over the study period.

\section{Statistics}

Descriptive statistics: The proportions, means and SD were used to describe the study population. ICS dosage equivalencies were classified into three categories according to the most recent Canadian Asthma Guidelines (3): low dose (fluticasone propionate of $250 \mu \mathrm{g} /$ day or less), medium dose (more than $250 \mu \mathrm{g} / \mathrm{day}$, up to $500 \mu \mathrm{g} / \mathrm{day}$ ) and high dose (higher than $500 \mu \mathrm{g} / \mathrm{day}$ ). The questionnaires were analyzed according to the methods described previously $(13,14)$.

Analysis of compliance: The data obtained from the first and last days of the study period were excluded. Then, for each day of use, the number of puffs recorded was extracted and the proportion (\%) of the prescribed daily dose that was actually inhaled was determined (ie, [inhaled/prescribed] $\times 100 \%$ ). The unadjusted compliance index was defined as the mean of the proportion of the prescribed daily dose that was actually inhaled ([inhaled/prescribed] $\times 100 \%$ ) over the study period. To prevent adherence scores from being artificially elevated by including excess usage, the compliance index was adjusted by recording no more than the maximum number of puffs prescribed on any given day, so that the maximum value for ([inhaled/prescribed] $\times 100 \%)$ was 100\% (Figure 1) (15). 
TABLE 1

Potential predictors of compliance to inhaled corticosteroids in adults with asthma

\begin{tabular}{|c|c|c|}
\hline Potential predictors & Measure instrument used & Comments/brief description \\
\hline Sociodemographics & Study-specific questionnaire & $\begin{array}{l}\text { Includes sex, age, civil status, level of education, personal or family income, } \\
\text { and type of drug insurance plan. }\end{array}$ \\
\hline \multicolumn{3}{|l|}{ Asthma severity } \\
\hline Asthma history & Study-specific questionnaire & $\begin{array}{l}\text { Includes duration of asthma, smoking status, prior asthma education } \\
\text { clinic attendance, previous participation in an asthma study, previous } \\
\text { hospitalization for asthma, use of peak flow meter and use of a written action plan. }\end{array}$ \\
\hline Pulmonary function & Spirometry $\left(\mathrm{FEV}_{1}\right)$ & $\begin{array}{l}\text { Spirometry was performed according to the American Thoracic Society } \\
\text { requirements (29). }\end{array}$ \\
\hline Asthma control & Asthma Control Questionnaire (ACQ) (13) & $\begin{array}{l}\text { The ACQ is a seven-item questionnaire (including spirometry) that measures } \\
\text { the adequacy of treatment. }\end{array}$ \\
\hline $\begin{array}{l}\text { Disease-specific quality of } \\
\text { life }\end{array}$ & $\begin{array}{l}\text { Standardized version of the Asthma } \\
\text { Quality of Life questionnaire } \\
\text { (AQLQ[S]) (30) }\end{array}$ & $\begin{array}{l}\text { The AQLQ(S) is a 32-item self-report questionnaire designed to measure the } \\
\text { problems that adults with asthma experience in their day-to-day lives. It is } \\
\text { composed of four domains: asthma symptoms, activity limitation, emotional } \\
\text { function and environmental exposure. }\end{array}$ \\
\hline \multicolumn{3}{|l|}{$\begin{array}{l}\text { Knowledge/attitudes toward } \\
\text { asthma (31-33) }\end{array}$} \\
\hline Knowledge/attitudes & $\begin{array}{l}\text { Same questionnaire as that used } \\
\text { by Boulet (31) }\end{array}$ & $\begin{array}{l}\text { Includes } 19 \text { items about various apsects of corticosteroids therapy, } \\
\text { particularly relating to the perceived modes of action and side effects }\end{array}$ \\
\hline Self-control & Self-Control Schedule $(34,35)$ & $\begin{array}{l}\text { From Rosenbaum's theory (35): people who succeed in maintaining a health } \\
\text { behaviour over an extended period of time can be distinguished from those who } \\
\text { failed based upon their relative level of learned resourcefulness. The Self-Control } \\
\text { Schedule is a } 36 \text {-item questionnaire that measures patients' self-control skills. }\end{array}$ \\
\hline \multicolumn{3}{|l|}{ Psychological factors (21) } \\
\hline Anxiety & $\begin{array}{l}\text { Spielberger's State-Trait Anxiety } \\
\text { Inventory (STAI) (36) }\end{array}$ & $\begin{array}{l}\text { The STAI is a self-report scale for measuring state and trait anxiety. The State- } \\
\text { Anxiety scale evaluates how respondents feel at this moment. The Trait-Anxiety } \\
\text { scale assesses how people generally feel. The current study limited its use to the } \\
\text { State-Anxiety scale. Both scales are usually highly correlated under } \\
\text { circumstances in which personal adequacy is evaluated (36). }\end{array}$ \\
\hline Depression & Symptom Checklist-90 (SCL-90) (37) & $\begin{array}{l}\text { The SCL- } 90 \text { contains } 90 \text { items relating to } 9 \text { different domains. The current study } \\
\text { limited its use of the SCL- } 90 \text { to the depression ( } 10 \text { items) and hostility (10 items) } \\
\text { domains (see below). }\end{array}$ \\
\hline $\begin{array}{l}\text { Problems with interpersonal } \\
\text { relationships }\end{array}$ & SCL-90 (37) & $\begin{array}{l}\text { Problems with interpersonal relationships may represent a reflection of negative } \\
\text { attitudes towards asthma and its treatment (including relationships with health } \\
\text { care staff). }\end{array}$ \\
\hline
\end{tabular}

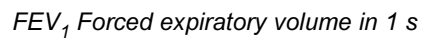

The cohort of patients was divided according to the adjusted index cut-off of $75 \%$ that was arbitrarily selected to define compliers ( $75 \%$ or higher) and noncompliers (less than 75\%) (2). The daily variation in ICS use was also examined by computing the SD of the unadjusted compliance index. An SD of the unadjusted compliance index (called the 'regularity index') of less than 50\% defined regular users, whereas patients with an SD of $50 \%$ or higher were defined as irregular users.

The cohort of patients was thus divided into four groups according to the adjusted compliance and regularity indexes. The 'regular compliers' comprised patients with an adjusted compliance index of $75 \%$ or higher and a regularity index of less than $50 \%$. The 'irregular compliers' included those with an adjusted compliance index of $75 \%$ or higher and a regularity index of $50 \%$ or higher. The 'regular noncompliers' were defined as patients with an adjusted compliance index of less than $75 \%$ and a regularity index of less than $50 \%$. The 'irregular noncompliers' were those with an adjusted compliance index of less than $75 \%$ and a regularity index of $50 \%$ or higher.

Logistic regression analysis was conducted to explain noncompliance using each of the potential predictors as independent variables. The linear correlation between the self-reported compliance and the adjusted index of compliance was also examined.
Sample size: It was anticipated that $50 \%$ of the study population would meet the definition of compliance. The authors sought to detect, in univariate logistic regression analyses, an OR of 2.0 or higher for noncompliance, with a power of $85 \%$. With statistical significance set at the 0.05 level, 125 patients were needed (16).

\section{RESULTS}

Potential predictors of compliance

Only five patients participated in the preliminary phase of the study that aimed to elicit the potential predictors of compliance to ICS. Their interviews did not result in the identification of any predictor other than those listed from the review of the literature and consultations with clinicians. Table 1 is a summary of the potential predictors of compliance with ICS identified in the preliminary phase of the study. The method of administration and the dosing regimen of ICS were excluded because by virtue of the inclusion criteria of the study and the electronic devices used, all patients were on a twice-daily regimen of inhaled fluticasone propionate delivered through metered-dose inhalers. These potential predictors clustered into four dimensions: sociodemographic; asthma severity; knowledge and attitudes towards asthma and its medication; and psychological variables. 


\section{TABLE 2}

\section{Baseline clinical characteristics of the patients with} asthma $(n=124)$

\begin{tabular}{|c|c|}
\hline \multicolumn{2}{|l|}{ Sociodemographic } \\
\hline Sex distribution (M:F) & $51: 73$ \\
\hline Age, years (mean $\pm S D)$ & $47 \pm 15$ \\
\hline Level of education, years (mean $\pm \mathrm{SD}$ ) & $13 \pm 4$ \\
\hline Public drug insurance plan (\%) & 44 \\
\hline \multicolumn{2}{|l|}{ Asthma history/severity } \\
\hline Time since the diagnosis of asthma, years (mean \pm SD) & $20 \pm 14$ \\
\hline Written action plan (\%) & 36 \\
\hline Prior asthma education clinic attendance (\%) & 67 \\
\hline Previous participation in an asthma study (\%) & 21 \\
\hline $\mathrm{FEV}_{1}(\%$ predicted; mean $\pm \mathrm{SD})$ & $78 \pm 21$ \\
\hline \multicolumn{2}{|l|}{ Inhaled steroids } \\
\hline Daily dose of fluticasone propionate, $\mu \mathrm{g}$ (mean $\pm \mathrm{SD}$ ) & $643 \pm 385$ \\
\hline \multicolumn{2}{|l|}{ Daily dose of fluticasone* } \\
\hline Low dose $\leq 250 \mu \mathrm{g} /$ day, $\mathrm{n}(\%)$ & $27(22)$ \\
\hline Medium dose $251 \mu \mathrm{g} /$ day to $500 \mu \mathrm{g} /$ day, $\mathrm{n}(\%)$ & $55(44)$ \\
\hline High dose $>500 \mu \mathrm{g} /$ day, $\mathrm{n}(\%)$ & $42(34)$ \\
\hline Long-acting beta-agonists, n (\%) & $8(6)^{\dagger}$ \\
\hline Antileukotrienes, n (\%) & $24(19)$ \\
\hline \multicolumn{2}{|l|}{ Asthma Quality of Life Questionnaire - Standardized (mean \pm SD) $)^{\ddagger}$} \\
\hline Asthma symptoms & $4.9 \pm 1.3$ \\
\hline Activity limitation & $5.3 \pm 1.1$ \\
\hline Emotional function & $5.5 \pm 1.2$ \\
\hline Environmental exposure & $5.0 \pm 1.3$ \\
\hline Asthma Control Questionnaire (mean $\pm \mathrm{SD})^{\S}$ & $1.8 \pm 1.2$ \\
\hline Knowledge about asthma (mean $\pm \mathrm{SD})^{\pi}$ & $2.8 \pm 0.6$ \\
\hline \multicolumn{2}{|l|}{ Psychological profile } \\
\hline State-Trait Anxiety Inventory (mean $\pm S D)^{\star \star}$ & $32.6 \pm 9.7$ \\
\hline \multicolumn{2}{|l|}{ Symptom Checklist-90†† } \\
\hline T score (mean \pm SD) & $56.3 \pm 10.3$ \\
\hline T scores $\geq 63, \mathrm{n}(\%)$ & $38(31)$ \\
\hline
\end{tabular}

*Inhaled corticosteroid (ICS) dosage equivalencies were classified into three categories according to the most recent Canadian Asthma Guidelines (3); tThis small proportion is attributed to the fact that patients taking an inhaler combining ICS and long-acting beta-agonists were excluded from the study; $¥$ Asthma Quality of Life Questionnaire (30) results are reported per domain on a 7-point scale, ranging from 1 - worst possible score to 7 - best possible score; §Asthma Control Questionnaire (13) results are reported on a 6-point scale, ranging from 6 - worst possible score to 0 - best possible score; "Knowledge about asthma was measured using a 19-item questionnaire about various aspects of corticosteroid therapy, particularly relating to the perceived modes of action and side effects (31); 0 - worst possible score; 4 - best possible score; ${ }^{* *}$ State-Trait Anxiety Inventory (36) scores range from 20 (the lowest level of anxiety) to 80 (the highest level of anxiety). Normal scores range from from 32 to 47 (36); ††Symptom Checklist-90 - depression (37): T scores of 63 or higher define 'depressive syndrome profile'. F Female; FEV ${ }_{1}$ Forced expiratory volume in $1 \mathrm{~s} ; \mathrm{M}$ Male

\section{Follow-up study}

Patients: One hundred thirty-four patients participated in the follow-up study. Ten were excluded because of defective electronic devices. Table 2 is a summary of the baseline clinical characteristics of the 124 patients who contributed to the analysis. No difference was observed in the patients' baseline characteristics across the study centres (Quebec City: $n=60$; Saguenay: $n=49$; Montreal: $n=15$ ).

Patterns of compliance: Including the excess doses, the patients took an average of $98 \pm 50 \%$ (range $5 \%$ to $327 \%$ ) of the prescribed medication daily. Excluding the doses in excess of the prescription, the mean adjusted compliance index was
$72 \pm 24 \%$ (range $3 \%$ to $100 \%$ ). On average, the patients were aware of their compliance behaviour (Self-reported

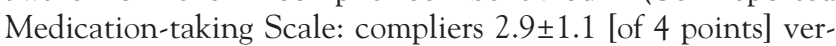
sus noncompliers $1.9 \pm 1.1 ; \mathrm{P}<0.0001)$. The self-recorded compliance ( $88 \pm 24 \%$; range $0 \%$ to $100 \%$ ) was usually higher than the measured indexes of compliance. The correlation between the adjusted compliance index and the self-reported compliance was moderate $(r=0.52, \mathrm{P}=0.0001)$. Of note, $21 \%$ of the patients disposed of the content of their inhaler the day before the follow-up visit.

Four patterns of compliance were observed and are described (Figure 2): 1A - regular compliance $(n=29$; mean adjusted compliance index $91 \%$; mean regularity index $36 \%$ ); $1 \mathrm{~B}$ - irregular compliance $(\mathrm{n}=37$; mean adjusted compliance index 90\%; mean regularity index 99\%); $2 \mathrm{~A}$ - regular noncompliance $(n=24$; mean adjusted compliance index 49\%; mean regularity index 33\%); and 2B - irregular noncompliance $(n=34$; mean adjusted compliance index $51 \%$; mean regularity index 124\%). From visual inspection of the compliance histograms, no patient had a period of complete or partial compliance followed by a period of complete noncompliance, a pattern that would have been compatible with nonrefilling of the ICS prescription.

Within the compliant and noncompliant groups, regular and irregular users did not demonstrate any differences. Among the potential predictors of noncompliance listed in Table 1 , only age reached statistical significance, with compliance increasing with increasing age (OR for noncompliance for one-year increments in age $0.95 ; 95 \%$ CI 0.93 to 0.98 ). No differences in asthma-specific quality of life or asthma control were detected between compliant and noncompliant patients, both at baseline and at the 12-week follow-up (Table 3). In a similar analysis comparing regular and irregular users of ICS, no differences in asthma-specific quality of life or asthma control were detected between the two groups, both at baseline and at the 12-week follow-up (Table 3).

\section{DISCUSSION}

Although complete information on the time measurement properties of the device was withheld, it is probable that the use of electronic devices increased the patients' compliance to ICS. In addition, our patients were recruited from specialty clinics and approximately $20 \%$ had previously participated in an asthma study. This suggests that they were not 'typical' asthma patients. For both reasons, our data may overestimate patients' usual compliance. Notwithstanding this situation, the results of our study indicate that compliance to ICS in asthma is generally suboptimal, at least in mild-to-moderate asthma.

Compliance to ICS is a complex phenomenon that is difficult to predict. Among the potential predictors of noncompliance, only age reached statistical significance, with compliance increasing with increasing age. Because the full spectrum of asthma severity was not equally represented in the study population, this may have hindered finding asthma severity as a predictive factor for compliance.

We relied entirely on the validity of compliance measurement through an electronic device. Several investigators (17-19) have reported on the validity of such devices, often with conflicting results. In a pilot study, we found that the MDILog II (Model MDC-512) accurately recorded the date and time of inhaler actuations (unpublished data). The fact that $21 \%$ of the patients disposed of the contents of their inhaler the day 


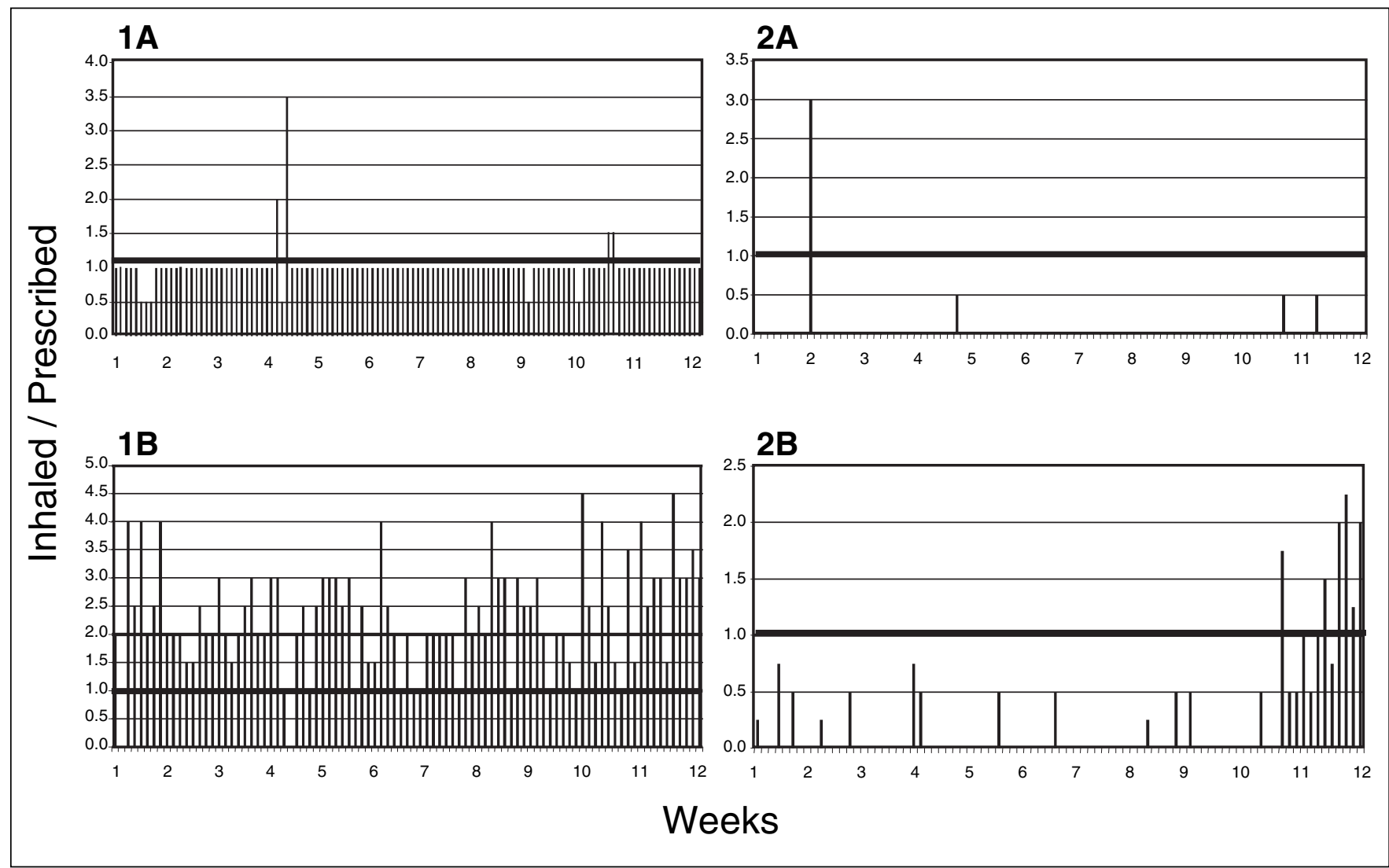

Figure 2) Patterns of compliance. Selected examples are provided. 1A Regular compliance (adjusted compliance index $97 \%$; regularity index $28 \%$ ); 1B Irregular compliance (adjusted compliance index 99\%; regularity index 92\%); 2 A Regular noncompliance (adjusted compliance index 3\%; regularity index 32\%); and 2B Irregular noncompliance (adjusted compliance index 19\%; regularity index 50\%)

TABLE 3

Quality of life and asthma control at the 12-week follow-up between compliers and noncompliers, and between regular and irregular users

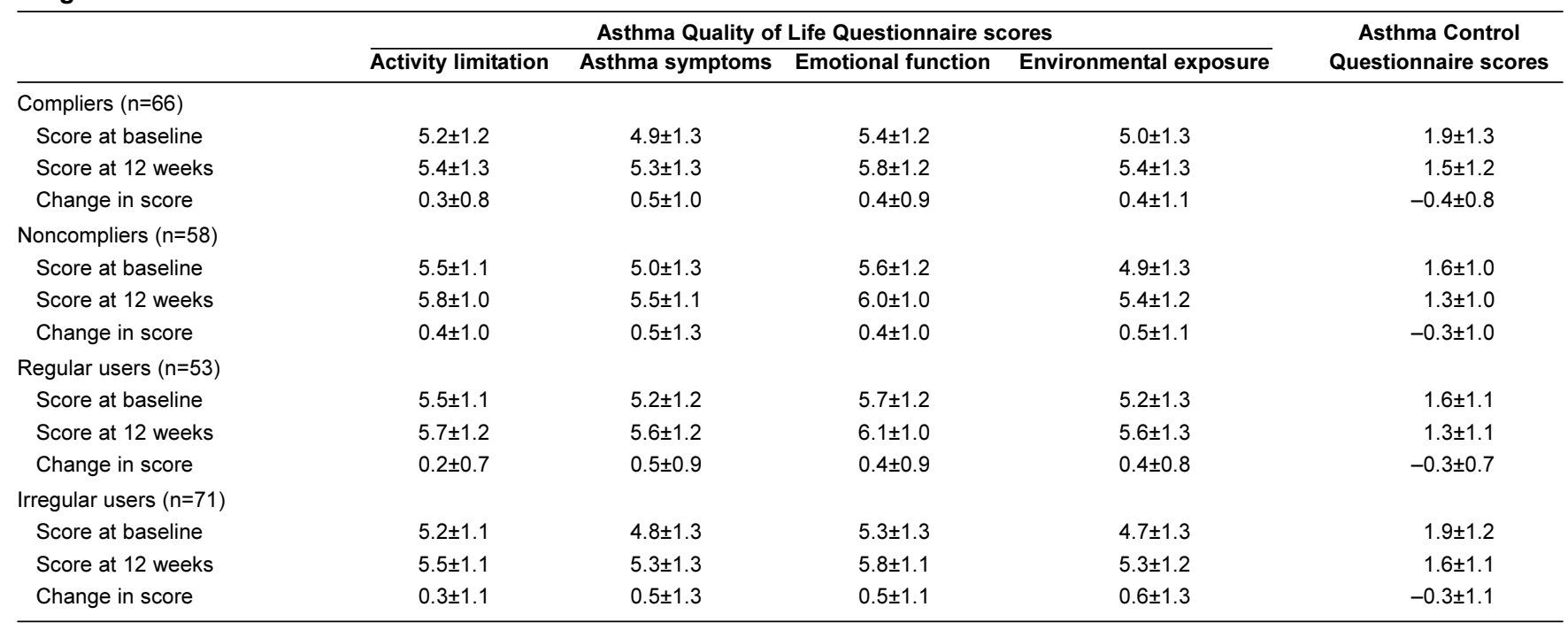

All scores are reported as mean \pm SD. None of the comparisons in scores between compliers versus noncompliers and between regular versus irregular users was significant

before the follow-up visit indicated that many remained unaware of the time measurement properties of the devices throughout the study.

Comparison with other studies

Overall, our results on compliance are in agreement with previous smaller studies in which electronic devices were employed to monitor compliance. Spector et al (20) found that the per cent of appropriate use ranged from $4.3 \%$ to $94.8 \%$, with only three of 19 patients using the medication appropriately on at least $70 \%$ of the days. Underusage greatly exceeded overusage, which could be appropriate in case of asthma exacerbations. Younger patients more frequently underused the aerosol than did the older subjects, which was also confirmed in the present findings. 
Other researchers have investigated reasons for noncompliance with asthma therapy, including social and economic factors. Bosley et al (21) reported that depression and interpersonal difficulties were among the factors that could discriminate compliers from noncompliers. However, the model they developed could correctly classify only $74 \%$ of the patients as either compliers or noncompliers. Apter et al (22) examined adherence to twice-daily inhaled steroid regimens in relation to sociodemographics, asthma severity and health locus of control in adults with moderate to severe asthma. Although this study appears similar to the present study, there were several key methodological differences. In Apter et al's study, the sample size was small $(n=50)$ and the observation period was only six weeks; as well, it was unclear who provided the medication to the patient and the patients were aware of the time measurement properties of the electronic devices. Up to four excess inhalations per day were allowed in the calculation of compliance. Ad hoc questionnaires were used to measure knowledge and attitudes towards ICS without prior validation. Surprisingly, several of the predictors of adherence were measured only at the end of the six-week adherence-measurement period. In univariate regression analyses, the authors found that the factors associated with poor adherence included a low level of education, poor patient-clinician communication, low income and minority status. The differences observed between Apter et al's study and the current study may arise from any or all of the methodological issues described.

\section{What are the consequences of poor ICS compliance in asthma?}

In children with asthma, a strong relationship between poor corticosteroid adherence and exacerbations of asthma has been reported (23). In adults with asthma, the evidence is less compelling. Although we did not record data on asthma exacerbations during the study period, no differences in scores on the Asthma Control and the Asthma Quality of Life questionnaires were detected between the adult compliers and noncompliers either at baseline or at the 12-week follow-up. This may result from the inability of both questionnaires to detect small but clinically significant differences. Another explanation would be that, on average, our patients were indeed 'overtreated', so that the control of asthma could be obtained with lower doses of ICS such as those taken by the noncompliers. In these patients, occasional symptoms may elicit medication-taking

\section{REFERENCES}

1. Haynes RB. Compliance in Health Care. Baltimore: Johns Hopkins University Press, 1979:1-7.

2. Cochrane GM. Observance and outcomes in patients with asthma. Drugs 1996;52(Suppl 6):12-9.

3. Lemière $\mathrm{C}, \mathrm{Bai} \mathrm{T}$, Balter $\mathrm{M}$, et al. Adult Asthma Consensus Guidelines Update 2003. Can Respir J 2004;11(Suppl A):9A-18A.

4. Juniper EF, Kline PA, Vanzieleghem MA, Ramsdale EH, O'Byrne PM, Hargreave FE. Effect of long-term treatment with inhaled corticosteroid (budesonide) on airway hyperresponsiveness and clinical asthma in nonsteroid-dependent asthmatics. Am Rev Respir Dis 1990;142:832-6.

5. Adams NP, Bestall JP, Jones PW. Inhaled beclomethasone at different doses for long-term asthma. Cochrane Database Syst Rev 2001;(1):CD002879.

6. Adams NP, Bestall JP, Jones PW. Fluticasone versus beclomethasone or budesonide for chronic asthma. Cochrane Database Syst Rev 2002;(1):CD002310. (Update in 2004;(2):CD002310)

7. Adams N, Bestall JM, Jones PW. Inhaled beclomethasone versus budesonide for chronic asthma. Cochrane Database Syst Rev 2002;(1):CD003530. behaviours. This phenomenon of "intelligent non-adherence" (24) is often promoted in asthma education clinics, where it is recommended that patients tailor their dose of ICS according to the self-perceived control of the disease (3).

\section{What if poor compliance is a real issue?}

A number of strategies have been developed to enhance patient compliance with asthma medication. These include: educating the patient; educating the patient's support group; providing cues and reminders; simplifying the treatment regimen; and providing comprehensive programs to foster compliance (8). There is little evidence to support the effectiveness of these strategies. Asthma patients who participated in a formal self-management program demonstrated only partial adherence to self-treatment guidelines (25). Similarly, there were no differences detected between compliers and noncompliers in the proportion of patients who had attended an asthma education clinic. It is a common belief that patient compliance with ICS may be enhanced by a combination treatment with a betaagonist. However, Bosley et al (26) could not confirm this hypothesis in a study of 72 patients.

Noncompliance in asthma may take several forms. Patients may fail to adhere to recommendations related to asthma trigger avoidance (27) or peak flow measurements (28). Determinants of noncompliance to nonpharmacological interventions may also differ from those of drug therapy. In addition, noncompliance to inhaled medication may have a bearing on the results and proper interpretation of clinical trials. Thus, clinicians remain challenged in their efforts to improve their assessment of asthma severity, the need for medication and compliance to anti-inflammatory therapy in patients who really need it on a regular basis.

ACKNOWLEDGEMENTS: The authors would like to thank the research assistants involved in this project: Christian Godbout (identification of the potential predictors), Céline Lepage, Muriel Grenon, Alexandra Hassan (follow-up study), Sylvie Martin (data management) and Serge Simard (statistical analysis), as well as the patients who participated in the study.

FUNDING: This study was supported by Towards Excellence in Asthma Management (TEAM), a program of the Quebec Asthma and COPD Network. TEAM was approved by the industrymatching fund program of the Fonds de la recherche en santé du Québec. TEAM is sponsored by Merck Frosst Canada Ltd.

8. Spector S. Noncompliance with asthma therapy - are there solutions? J Asthma 2000;37:381-8.

9. Standards for the diagnosis and care of patients with chronic obstructive pulmonary disease (COPD) and asthma. This official statement of the American Thoracic Society was adopted by the ATS Board of Directors, November 1986. Am Rev Respir Dis 1987;136:225-44.

10. Guillemin F, Bombardier C, Beaton D. Cross-cultural adaptation of health-related quality of life measures: Literature review and proposed guidelines. J Clin Epidemiol 1993;46:1417-32.

11. Nides MA, Tashkin DP, Simmons MS, Wise RA, Li VC, Rand CS. Improving inhaler adherence in a clinical trial through the use of the nebulizer chronolog. Chest 1993;104:501-7.

12. Levine RJ. Monitoring for adherence: Ethical considerations. Am J Respir Crit Care Med 1994;149:287-8.

13. Juniper EF, O'Byrne PM, Guyatt GH, Ferrie PJ, King DR. Development and validation of a questionnaire to measure asthma control. Eur Respir J 1999;14:902-7. 
14. Morisky DE, Green LW, Levine DM. Concurrent and predictive validity of a self-reported measure of medication adherence. Med Care 1986;24:67-74.

15. Bender B, Wamboldt FS, O'Connor SL, et al. Measurement of children's asthma medication adherence by self report, mother report, canister weight, and Doser CT. Ann Allergy Asthma Immunol 2000;85:416-21.

16. Hsieh FY. Sample size tables for logistic regression. Stat Med 1989;8:795-802.

17. Brueckner JW, Marshik P, Sherman J, Hendeles L. Reliability of the Medtrac MDI Chronolog. J Allergy Clin Immunol 1997;100:488-91.

18. Wamboldt FS, Bender BG, O'Connor SL, et al. Reliability of the model MC-311 MDI chronolog. J Allergy Clin Immunol 1999; 104:53-7.

19. Julius SM, Sherman JM, Hendeles L. Accuracy of three electronic monitors for metered-dose inhalers. Chest 2002;121:871-6.

20. Spector SL, Kinsman R, Mawhinney H, et al. Compliance of patients with asthma with an experimental aerosolized medication: Implications for controlled clinical trials. J Allergy Clin Immunol 1986;77:65-70.

21. Bosley CM, Fosbury JA, Cochrane GM. The psychological factors associated with poor compliance with treatment in asthma. Eur Respir J 1995;8:899-904.

22. Apter AJ, Reisine ST, Affleck G, Barrows E, ZuWallack RL. Adherence with twice-daily dosing of inhaled steroids: Sociodemographic and health-belief differences. Am J Respir Crit Care Med 1998;157:1810-7.

23. Milgrom H, Bender B, Ackerson L, Bowry P, Smith B, Rand C. Noncompliance and treatment failure in children with asthma. J Allergy Clin Immunol 1996;98:1051-7.

24. Hindi-Alexander M. Compliance or noncompliance: That is the question! Am J Health Promot 1987;1:5-11.

25. van der Palen J, Klein JJ, Rovers MM. Observance with inhaled medication and self-treatment guidelines following a selfmanagement programme in adult asthmatics. Eur Respir J $1997 ; 10: 652-7$.
26. Bosley GM, Parry DT, Cochrane GM. Patient compliance with inhaled medication: Does combining beta-agonists with corticosteroids improve compliance? Eur Respir J 1994;7:504-9.

27. Desjardins A, Benoit C, Ghezzo H, et al. Exposure to domestic animals and risk of immunologic sensitization in subjects with asthma. J Allergy Clin Immunol 1993;91:979-86.

28. Verschelden P, Cartier A, L'Archeveque J, Trudeau C, Malo JL. Compliance with and accuracy of daily self-assessment of peak expiratory flows $(\mathrm{PEF})$ in asthmatic subjects over a three month period. Eur Respir J 1996;9:880-5.

29. Standardization of Spirometry, 1994 Update. American Thoracic Society. Am J Respir Crit Care Med 1995;152:1107-36.

30. Juniper EF, Buist AS, Cox FM, Ferrie PJ, King DR. Validation of a standardized version of the Asthma Quality of Life Questionnaire. Chest 1999;115:1265-70.

31. Boulet LP. Perception of the role and potential side effects of inhaled corticosteroids among asthmatic patients. Chest 1998;113:587-92.

32. Hand $\mathrm{CH}$, Bradley C. Health beliefs of adults with asthma: Toward an understanding of the difference between symptomatic and preventive use of inhaler treatment. J Asthma 1996;33:331-8.

33. Osman LM, Russell IT, Friend JA, Legge JS, Douglas JG. Predicting patient attitudes to asthma medication. Thorax 1993;48:827-30.

34. Lévesque L, Desharnais R, Godin G. Validation canadiennefrançaise du self-control schedule. Science Comportement 1995;24:133-49.

35. Rosenbaum M. A schedule for assessing self-control behaviors: Preliminary findings. Behav Ther 1980;11:109-21.

36. Spielberger CD, Gorsuch RL, Lushene RE, et al. Manual of the State-Trait Anxiety Inventory. Palo Alto: Consulting Psychologists Press, 1983

37. Derogatis LR, Cleary PA. Confirmation of the dimensional structure of the SCL-90: A study in construct validity. J Clin Psychol $1977 ; 33: 981-9$ 


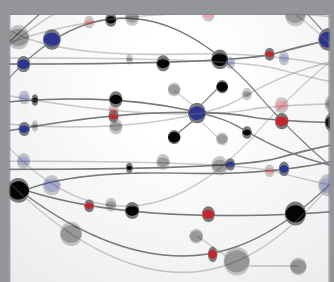

The Scientific World Journal
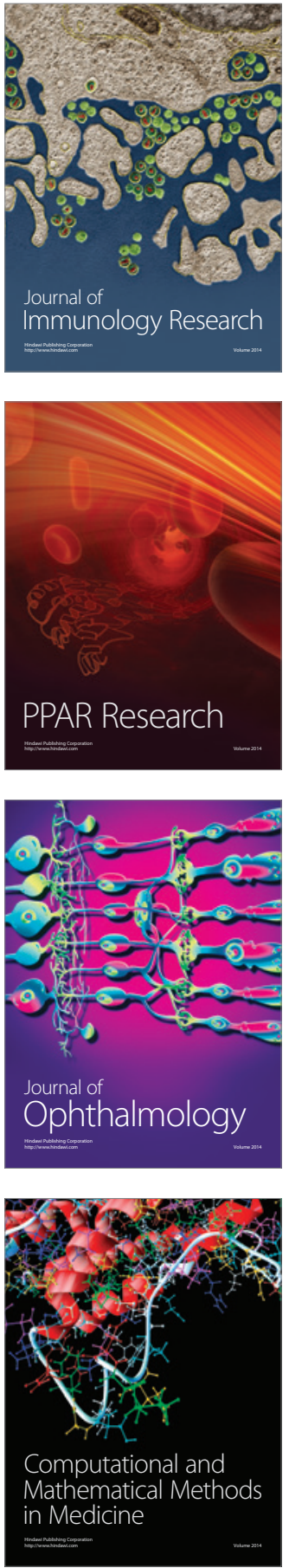

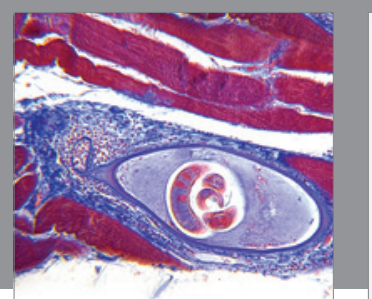

Gastroenterology Research and Practice

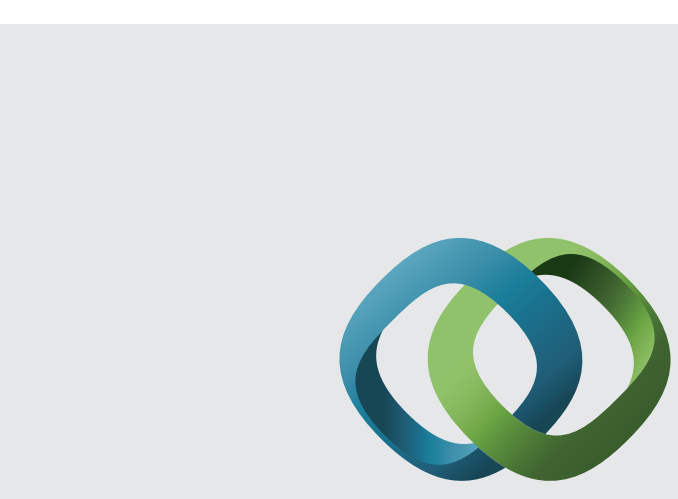

\section{Hindawi}

Submit your manuscripts at

http://www.hindawi.com
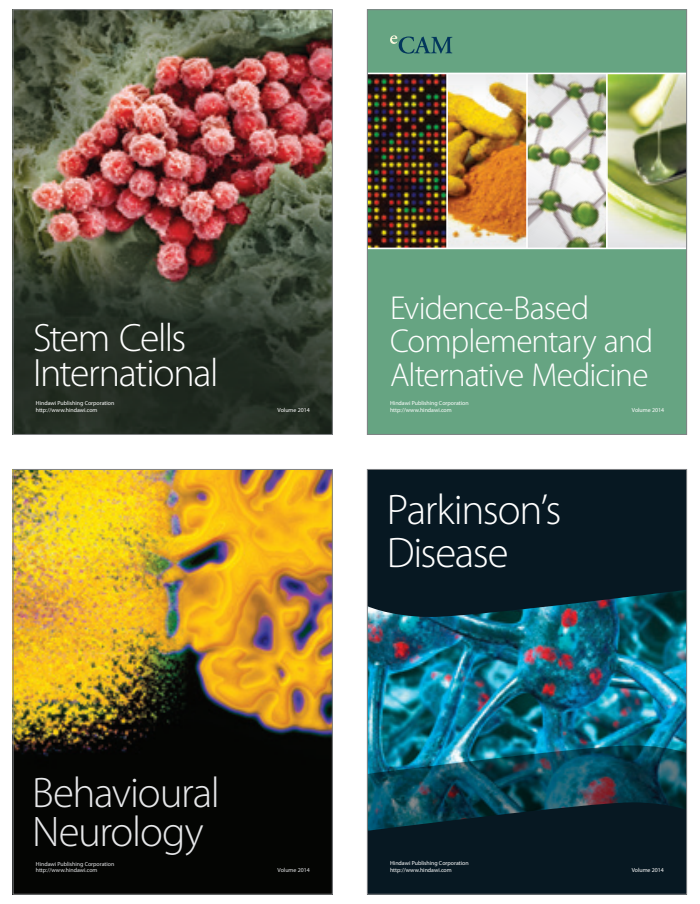
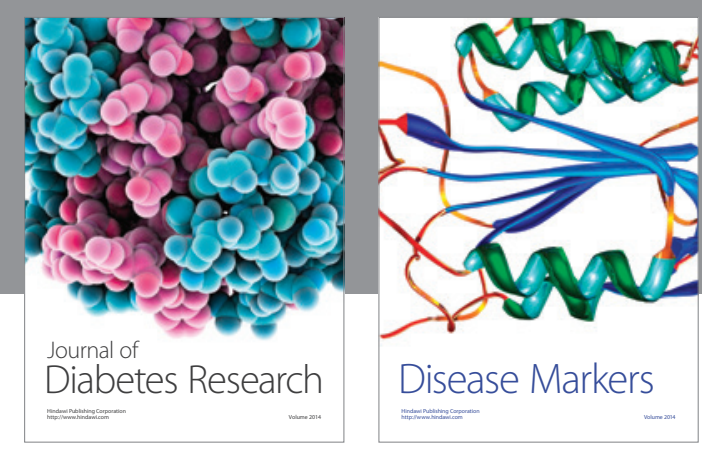

Disease Markers
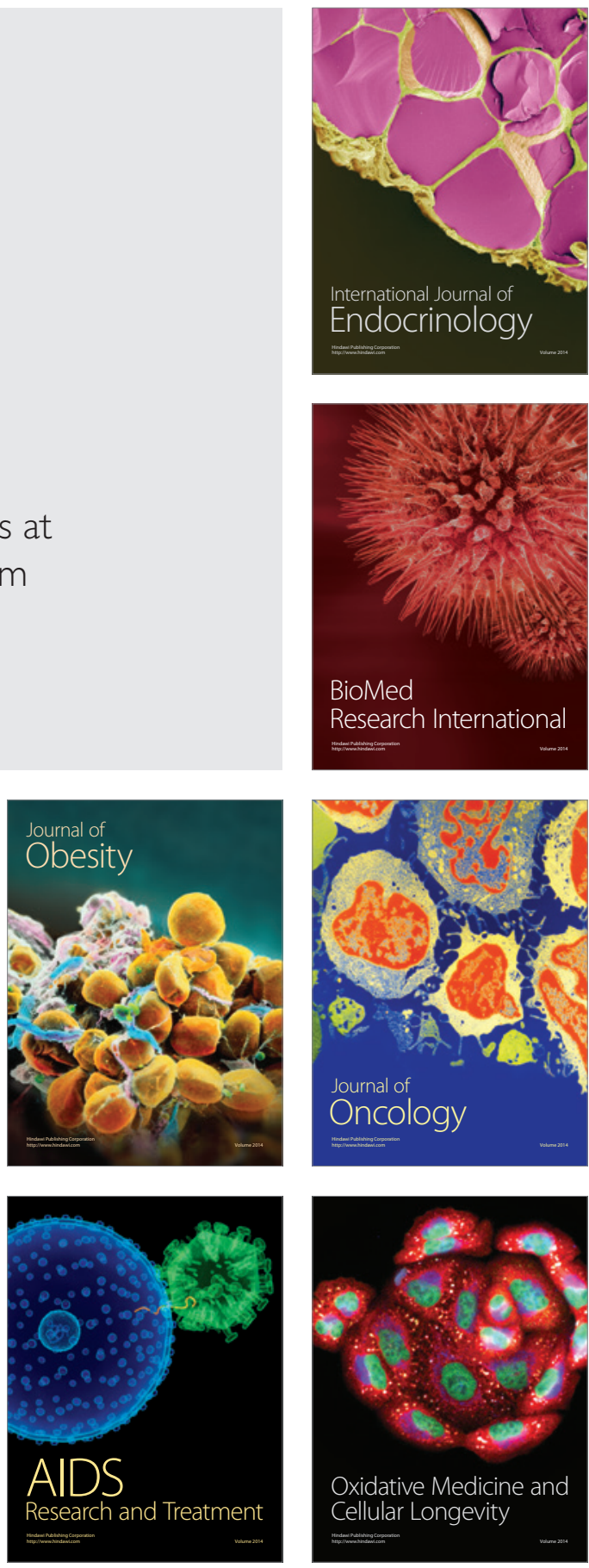